\title{
Evaluation of the Effect of Implant-numbers, Position and Complete Over Denture on Alveolar Bone Resorption.
}

\begin{abstract}
The aims: The aims of this study were to evaluate the alveolar bone resorption every $2.5 \mathrm{~mm}$ distal to the implant over denture to the retromolar pad in the mandibular arch, and to the maxillary tuberosity in the maxillary arch in edentulous patient according to number between two and four, and position of implants between canine and $2^{\text {nd }}$ premolar. Materials and Methods: Eight patients (age range 45-60 years) were selected from the department of Prosthodontics/ College of Dentistry/Mosul University, who had at least one edentulous arch. All patients complaining from poorly retention conventional acrylic complete denture due to the residual ridge resoption, but the alveolar ridge height need at least $10 \mathrm{~mm}$ implant length.After completing the surgical steps of 26 implants (two or four implant screw type titanium), over denture type with one step surgery for all implant types were constructed in conventional method after one month healing period. The prosthesis was delivered to the patients after one months of making the period elapsed. Dentures were delivered without socket attachment(six months). For assessment of alveolar bone height, for each patient panoramic exposure of OPG was recorded - three times [base line(at time of placement) , 6 months and 12 months]. Results: Results of this study showed, that mean difference of bone resoption range between [-0.2 -(-0.6)mm], and there was a significant difference of bone resoption between base line and 12 months to $\mathrm{p} \leq 0.05$ according to number and position of implants. Conclusions: The conclusion of this study showed that, there was no significant different of alveolar ridge bone resoption between implants number in two or four implants over denture or implant position.
\end{abstract}

| الخلاصة

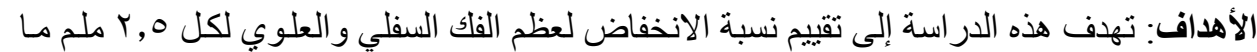

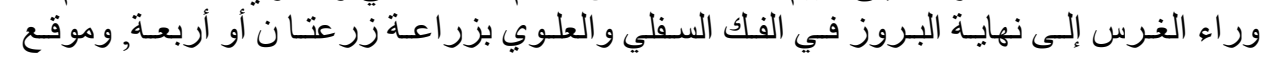

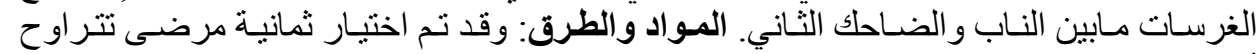

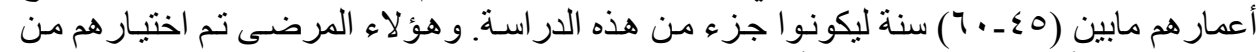

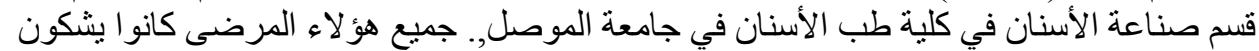

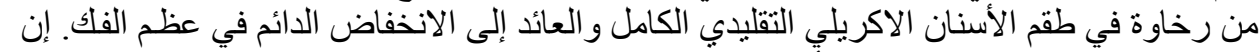

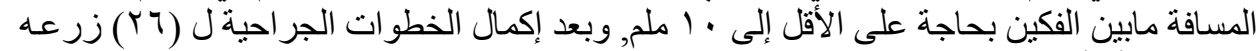

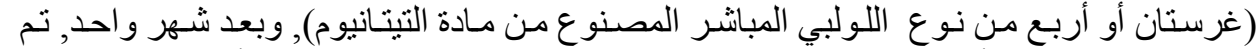

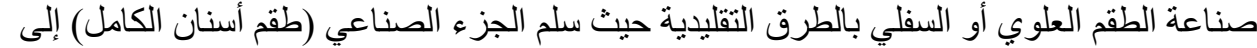

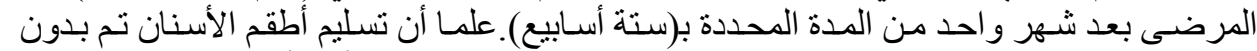

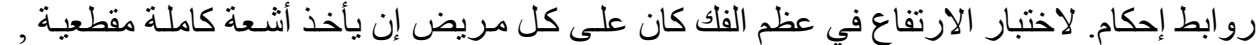

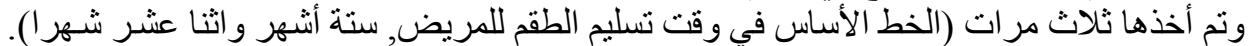

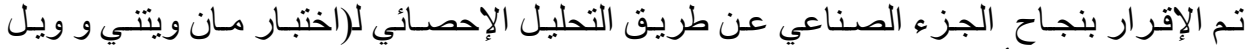

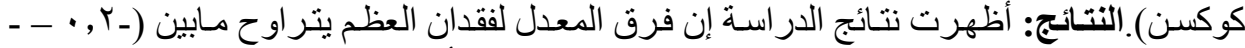

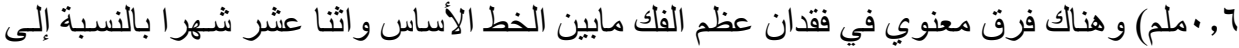

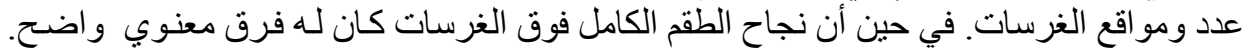

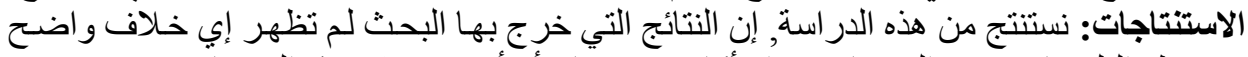

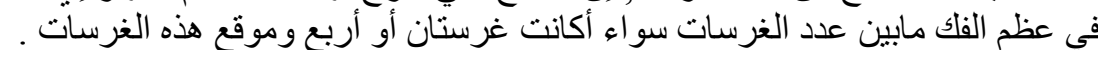

Key words: implant number and position, in vivo study, implant overdenture.

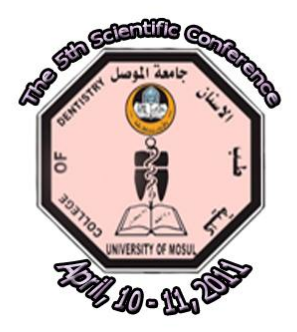

Prof Nadira A. Hatim $(B D S$, , MSc $)$; Ali M. AlSheakh (BDS, HDD)
Department of Prosthodontics, Dentistry College, Mosul University 
mplant-supported denture is a type of over denture that is supported by and attached to implants ${ }^{(1)}$. Attachments used with a minimal number of implants are dependent on the denturebearing capacity of the soft tissue and the relative movements that may be allowed by differential support. These attachments should be durable and easily replaced ${ }^{(2)}$. The most common position is situated around canines as a high bone volume is associated to a sufficient lingual prosthetic one in this area. However, when this choice is not possible, an incisor or a premolar position is adopted $^{(3)}$. One of the safe and economical solutions is the variant with two implants in the front area of $\operatorname{arch}^{(4,5)}$.

Bone resorption in edentulous alveolar processes has been studied extensively it is conclude that it is a chronic, progressive and irreversible process that occurs in all patients ${ }^{(6)}$. There are many methods to estimate alveolar bone height ${ }^{(7-9)}$.

It is postulated that OPGs should be used with caution ${ }^{(10,11)}$. Vertical measurements using panoramic radiographs are clinically applicable in quantitative assessment of alveolar bone height in the mandible and maxilla ${ }^{(12)}$. Panoramic examination can be considered a safe preoperative evaluation procedure for routine posterior mandibular implant placement. Panoramic radiography is a quick, simple, low-cost and low-dose presurgical diagnostic tool. When a safety margin of at least $2 \mathrm{~mm}$ above the mandibular canal is respected. Panoramic radiography appears to be sufficient to evaluate available bone height before insertion of posterior mandibular implants and cross-sectional imaging techniques may not be necessary ${ }^{(13)}$.

The aims of this study were to evaluate the alveolar bone resorption every $2.5 \mathrm{~mm}$ distal to the implant over denture (either to the retromolar pad in the mandibular arch or maxillary tuberosity in the maxillary arch among edentulous patient) according to number and position of implants.

\section{MATERIALS AND METHODS}

Twenty six implants of one stage surgery made of titanium (OVD- LEADER ITALY) were used in this study. The length, diameter and Bach number are shown in Table (1).

Experimental Design: The experimental design of this study was to construct implant supported overdenture with stud attachments and shown in Figures (1 and.2).

Eleven patients were chosen to be included in this study, meanwhile only eight patients continued to the end of the study. The eight patients (4 male, and 4 female but one of the male patient had maxillary and mandibular cases) were selected at the. Department of Prosthodontics /College of Dentistry/ Mosul University, who had at least one edentulous arch. These patients had an age between (45- 60) years old, and had a medical history that did not contraindicate implant treatment, complaining from poorly retention conventional acrylic complete denture, due to residual ridge resoption, but the alveolar ridge height need at least $10 \mathrm{~mm}$ implant length ${ }^{(14)}$. The implant number and position were chosen between two or four implants ${ }^{(15)}$.

All the patients with the followings criteria: (the last extraction performed was more than five years. Normal healed mucosa without needing to augment the mandible with simultaneous bone graft in the canine and $2^{\text {nd }}$ premolar regions.Completely edentulous maxilla or mandible with normal class I relation and without any history of bruxism occlusion. Occlusal surfaces in the opposing jaw are supported by either natural, artificial teeth or implants. Bone volume limited in width, height, or otherwise insufficient for bilateral implant placement in the posterior mandible.Maintenance of good oral hygiene by scaling and polishing of the remaining natural teeth. Prepare implant position and angulations by acrylic surgical templates, the implant angle ranged between $0-15$ degree angle $\left.{ }^{(16)}\right)$. 
Patient medication is given before operation like diazepam ( $2 \mathrm{mg})$. The patient was evaluated preoperatively with respect to jaw size by study cast, bone quality/volume, soft tissue evaluation by sterile fine endodontics reamer, jaw relations, maxillomandibular distance, and occlusion.

Preoperative analysis of anatomic conditions was performed with Digitized panoramic radiographs (OPG) orthopantograms ${ }^{(17)}$, as in (Figure 3).

After one months, complete maxillary with palatal cover or mandibular complete denture was constructed in the conventional methods. The Open-mouth technique were made of the maxillary and mandible alveolus impression by using silicon impression material (heavy and light bodyZeta pluse; Italy) after two weeks from the surgical procedure ${ }^{(18)}$. The use of tactile sense and patient-perceived comfort to obtain horizontal and vertical maxillomandibular records ${ }^{(19)}$. The trial arrangement was evaluated intra orally for esthetics, phonetics, occlusal vertical dimension, and centric relation. After curing, the polymerized prosthesis was finished and polished. The prosthesis was checked in patients mouth and improving mature contact with all teeth to prevent any premature contact ${ }^{(20)}$.

The prosthesis was delivered to the patients after one months of making the period elapsed, six weeks between the surgical procedure and delivery of the denture. Dentures were delivered without socket attachment ${ }^{(21,22)}$. Try to increase the diameter of implant holes in denture base to decrease friction with implant ball head attachment, as in Figure (4). After six months from denture placement, stud attachments were delivered by using the aluminum foil and spacer protects the sulcus from resin's penetration to implant head (Figures 5 and 6$)^{(23)}$. Slight mini holes drilled in lingual side of maxillary and lower dentures to enable excess resin cold cure to escape when loading elastic socket attachment, then the dentures were processed and finished.

\section{Panoramic Radiographic Procedure:}

Panoramic radiographs were taken at the scheduled visits ${ }^{(6,24)}$ :

1. The day of insertion of the complete dentures (baseline level). Between $1^{\text {st }}$ and $2^{\text {nd }}$ steps, in this period multiple adjustments for patient improved to provide comfortable occlusion to prevent any abnormal occlusion to implant which was made for just retention as in catalog.

2. After six months, elastic socket attachment was inserted.

3. Third step after 12 months when patient relaxed without any uncomforting with continuous instruction of good oral hygiene.

The marginal bone level, relative to the implant reference point (Middle implant tip of the ball), as shown in Figure (7) measured distal to the implants at $2.5 \mathrm{~mm}$ seven records after $2^{\text {nd }}$ premolar and nine records after canine reach to the beginning of retromolar pad area in mandibular arch and maxillary tubrosity area in maxillary arch points. By using digitized panoramic radiographs, the measurements were performed with the aid of a digital image processing method (DIMAX Dental Office Software). The marginal bone level was radiographically determined at three time points: at prosthetic placement (baseline level), after six months and follow-up continued to the end of 12 months. Assessment of Alveolar Bone Height: For each patient panoramic, exposure of OPG was recorded - three times (base line, 6 monthss and 12 monthss).

$\mathbf{1}^{\text {st }}$ step measuring: This procedure was done after fixation of stainless steel wire (10mm lengthgauge 0.7 ) in a prepared groove mesial to upper or mandibular $1^{\text {st }}$ molar in maxillary or mandibular complete denture for each patient before taking panoramic x-ray (Figure 8). The patient head was fixed in the panoramic machine (the patient to wear the prosthesis in his/her mouth to stabilize bit block in the same vertical dimension). Panoramic exposure at the delivery of prosthesis (base line) then saves the image in Dimax program. 
To stabilize any image of two dimensions this needs vertical and horizontal stabilization, this can be achieved by fixed intra oral implant and fixed horizontal plane from the $1^{\text {st }}$ image distal to the implant ended to the retro molar area in mandible and maxillary tubrosity in maxillary arch (Figure 9) .

Start measurement by changing the caliber for each side of arch and start the line from the middle of implant tip and classified the horizontal plan into (every $2.5 \mathrm{~mm}$ ) with 0 degree angle after recording the length. Then in every $2.5 \mathrm{~mm}$ measure, the perpendicular plan ( 90 degree) ended at the crest of the ridge bone and recorded. But the $1^{\text {st }} 2.5 \mathrm{~mm}$ measurement was neglected from the study and cannot be recordable within one year because alveolar bone resorption at this area and time not on normal range ${ }^{(25)}$ as in Figure (10).

The $2^{\text {nd }}$ and $3^{\text {rd }}$ Steps Measuring: After six months, and 12 months panoramic images were repeated for each patient with the same caliper of the $1^{\text {st }}$ step to improve standardization and record all measurements in computer, and statistical methods were used to analyze and assess the results via SPSS V. 11.5.

Table (1): Surgical implant materials used in this study

\begin{tabular}{ccccc} 
Type of implants & $\begin{array}{c}\text { Length } \\
\text { mm }\end{array}$ & $\begin{array}{c}\text { Implant } \\
\text { dimension }\end{array}$ & $\begin{array}{c}\text { Number of } \\
\text { implant used }\end{array}$ & Batch No. \\
Implant with spherical Head & 10 & 3.7 & 18 implants & 011 No2711 \\
Implant with spherical Head & 11.5 & 3.7 & 7 implants & 011 No3711 \\
Implant with sphericalHead & 13 & 3.7 & 1 implant & 011 No5711 \\
\hline
\end{tabular}

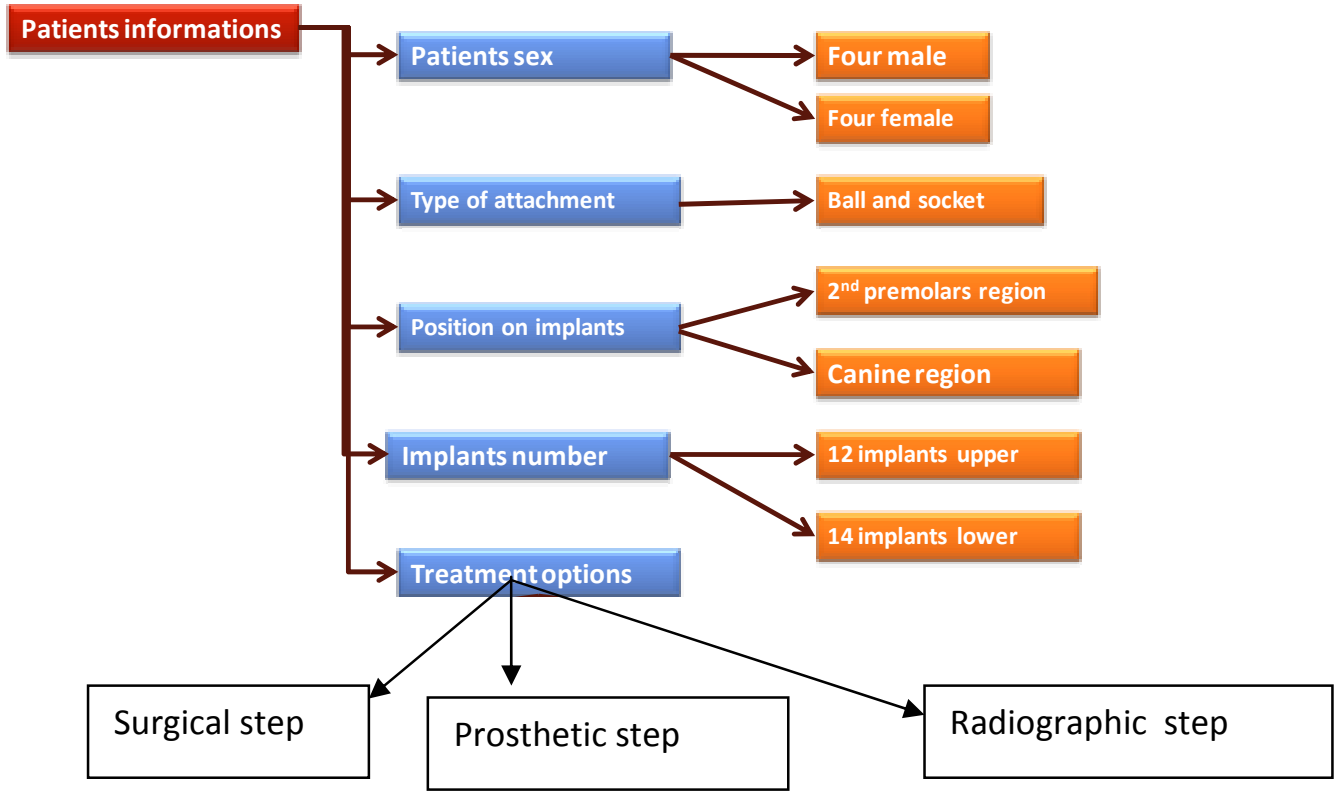

Figure (1): Experimental design of Patients information's. 


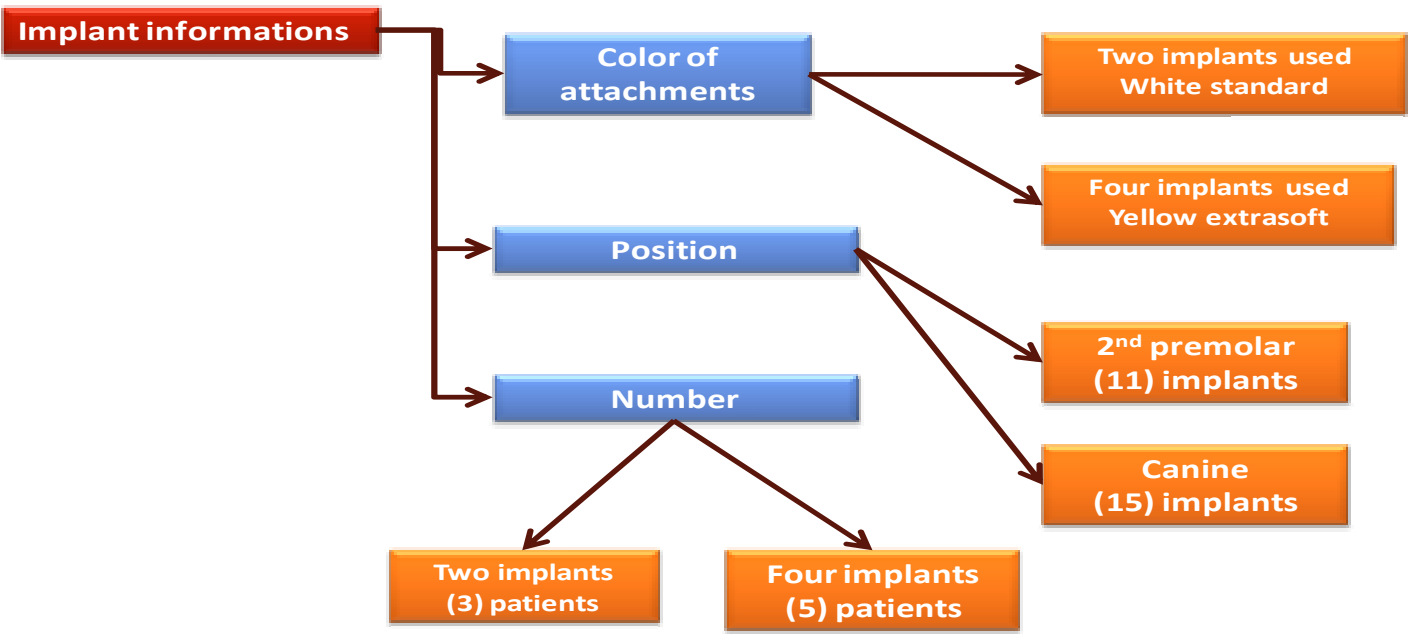

Figure (2): Implant, number, position and color of attachments.

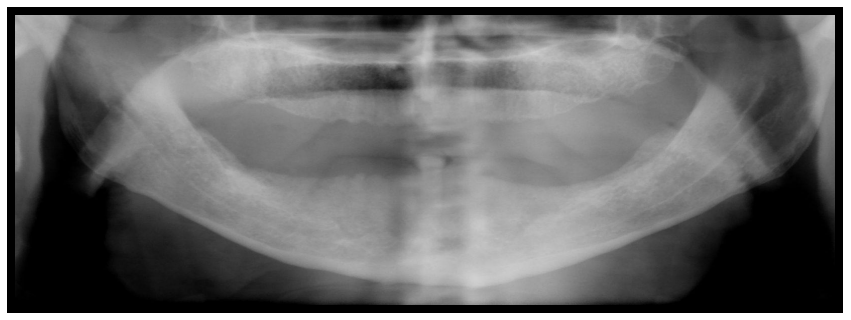

Figure (3): Diagnostic OPG of patient.

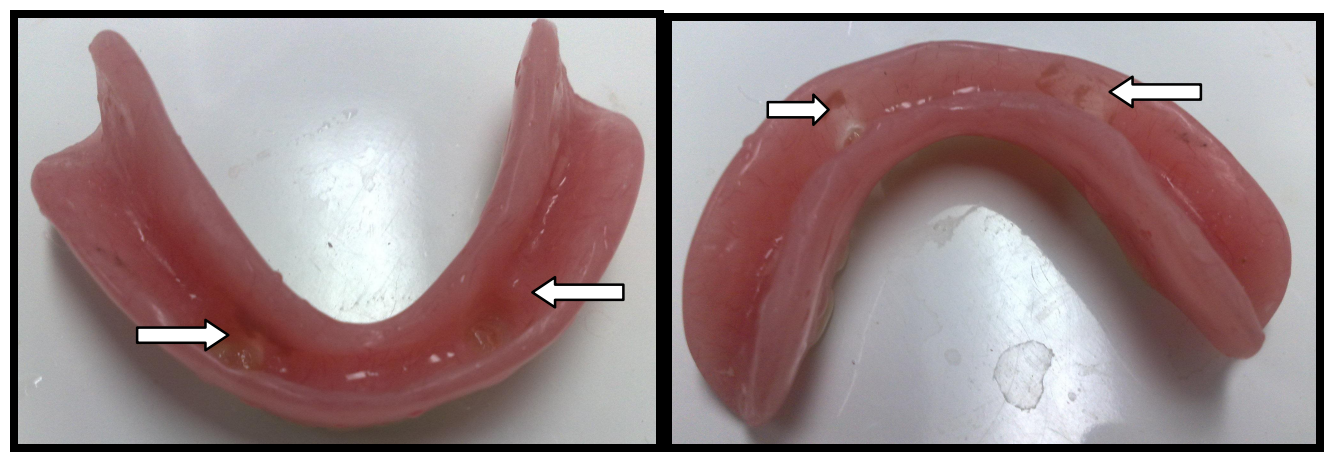

Figure (4): Delivery, Dentures without socket attachment 
Hatim NA, Al-Sheakh AM

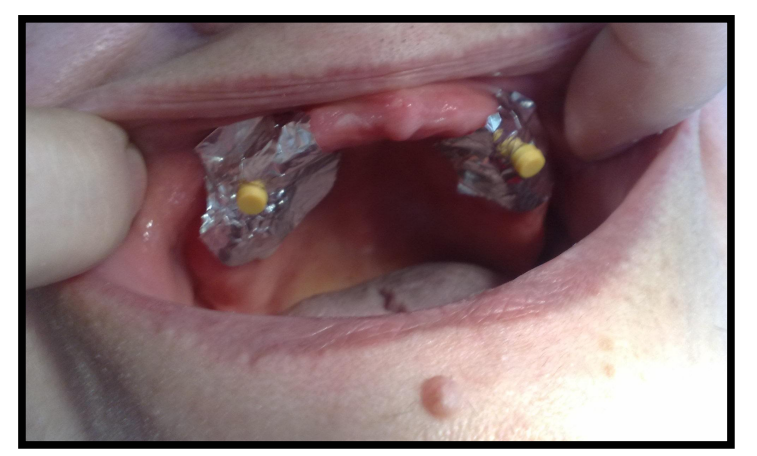

Figure (5): Two implant with stud and selofan

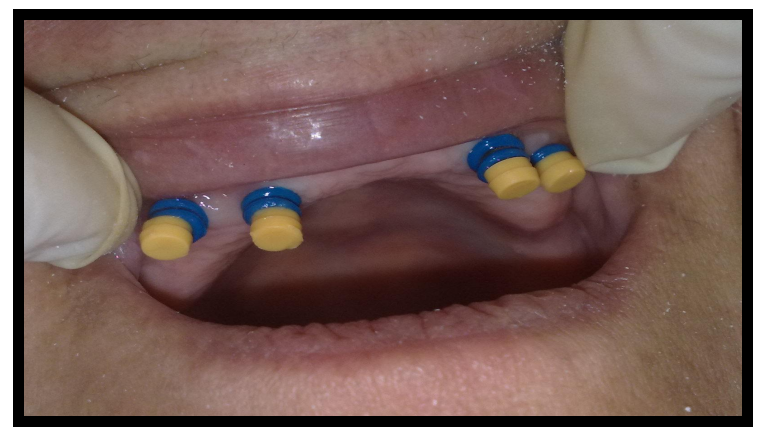

Figure (6): Four implant with stud and spacer.

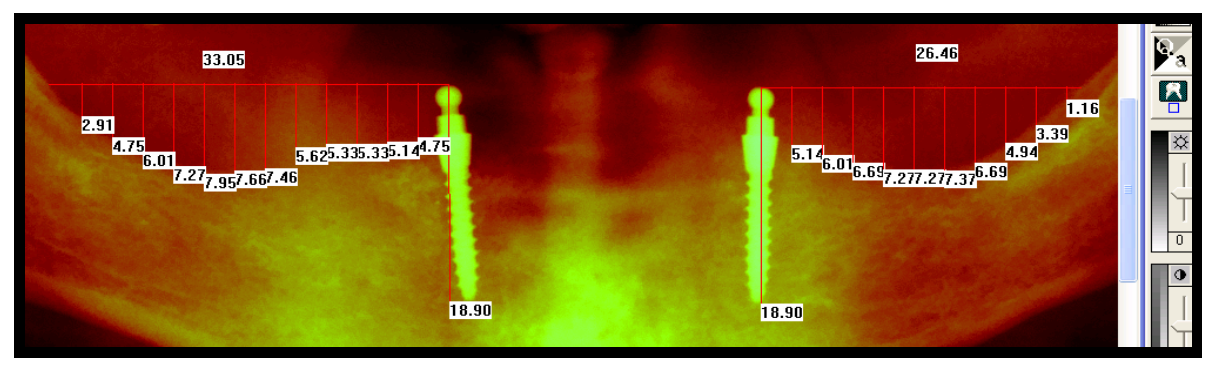

Figure (7): Two implant in dimax program.

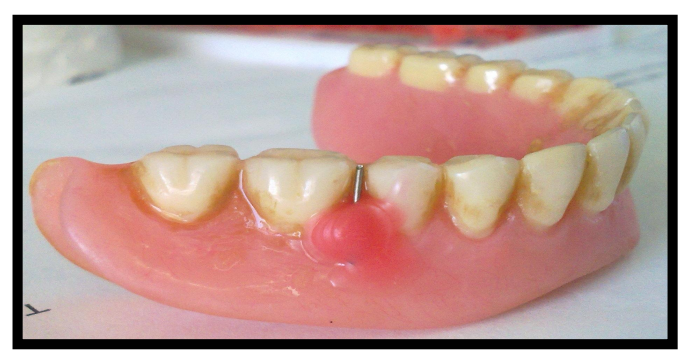

Figure (8): Stainless steel wire 10mm. fixed with wax. 


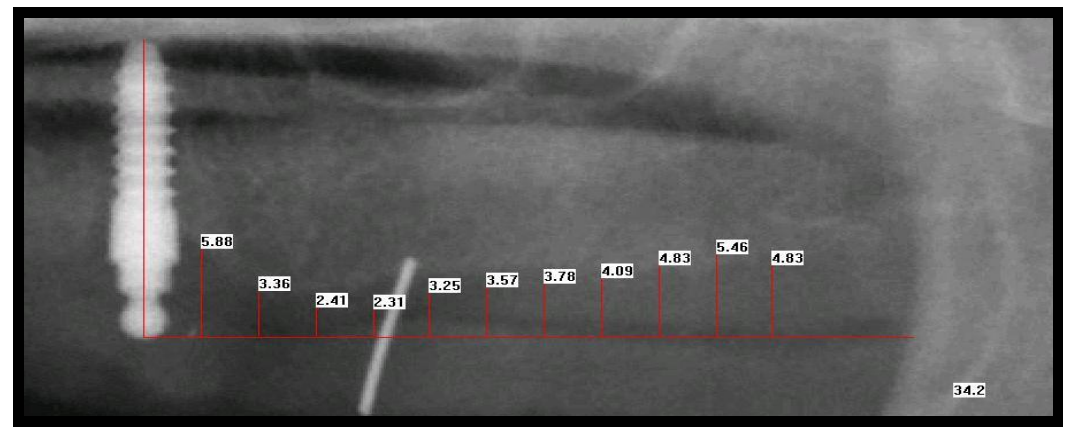

Figure (9): Dimax program with fixed caliper.

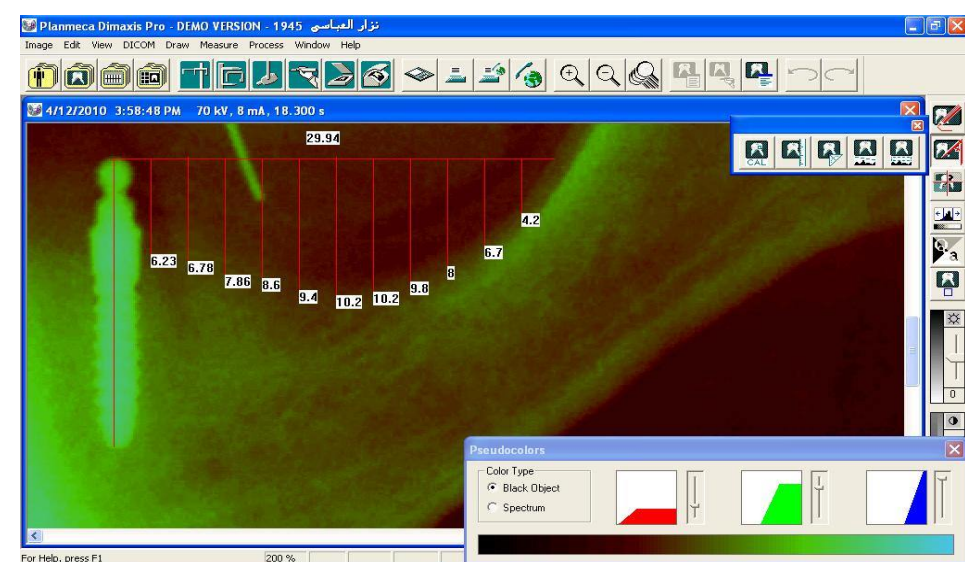

Figure (10): Every $2.5 \mathrm{~mm}$ perpendicular plan and record.

\section{RESULLTS \\ Correlation between Implant Numbers and Effect on Alveolar Bone Resoption: Two vs. Four Implants Overdenture:}

Concerning the number of implants and their effect on alveolar bone resorption figures (1113) demonstrated descriptive statistics; meanwhile Table (2) demonstrated significant difference $(p \leq 0.05)$ on alveolar bone resorption between two implants versus four implants at readings after 6 months and after 12 months. Also, there was significant difference $(p \leq 0.05)$ at last reading after 1 year. There was no significant difference $(p>0.05)$ between the two implants and four implants at other readings.

\section{Correlation between Implant Position and Effect on Alveolar Bone Resoption:} Canine vs. $2^{\text {nd }}$ Premolar Implant Overdenture:

Concerning the position of implants and their effect on alveolar bone resorption figures (14-16) demonstrated descriptive statistics. Mean while, table (3) demonstrated no significant difference $(p>0.05)$ on alveolar bone resorption between canine implant versus $2^{\text {nd }}$ premolar implant at all readings. 


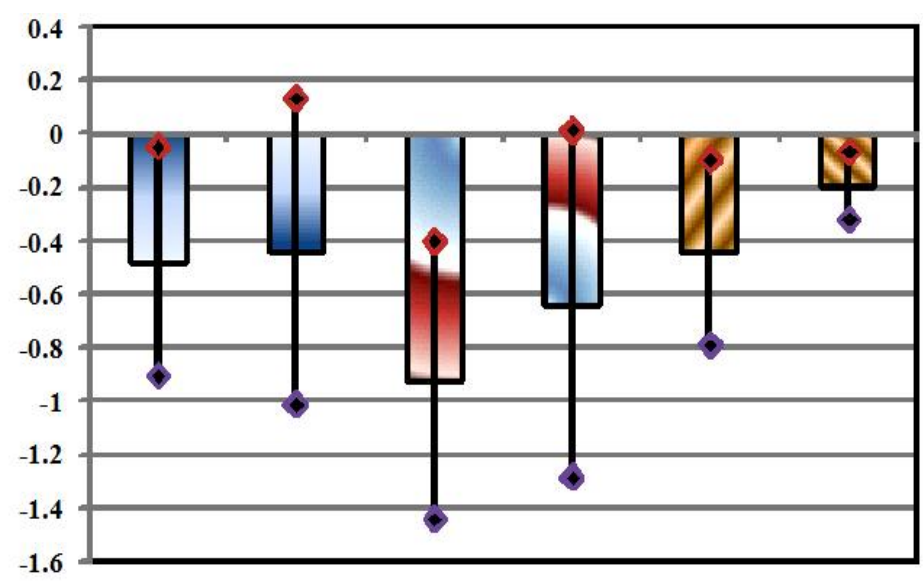

Figure (11): Descriptive statistics concerning mean difference of implant numbers and effect on alveolar bone resoption between baseline and after 6 months, between baseline and after 1 year and between after 6 months and 12 months(implant number).

2 Implants 4 Implants 2 Implants 4 Implants 2 Implants 4 Implants
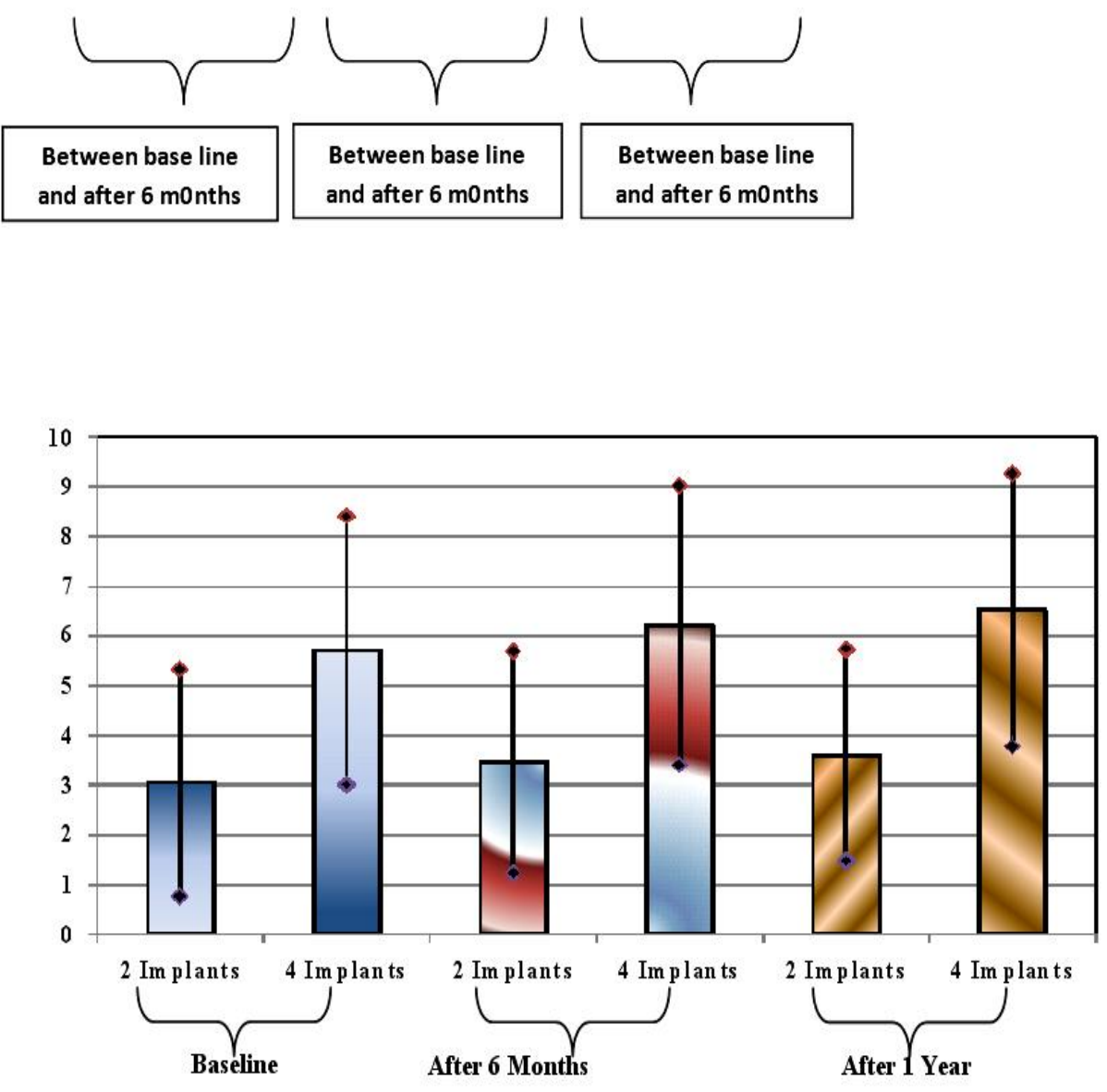

Figure (12): Descriptive statistics of implant numbers and effect on alveolar bone resoption at first readings: baseline, after 6 months and after 12 months(implant number). 


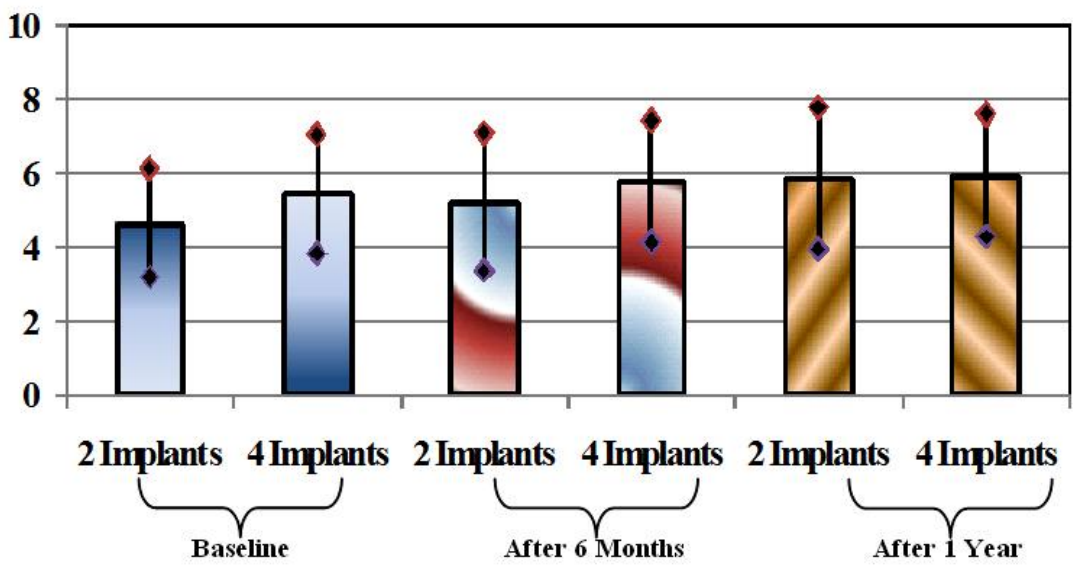

Figure (13): Descriptive statistics of implant numbers and effect on alveolar bone resoption at last readings: baseline, after 6 months and after 12 months(implant number).

Table (2): Student's t-test two implants vs. four implants

\begin{tabular}{|c|c|c|c|}
\hline 2 implants vs. 4 implants & t-value & d.f. & $p$-value \\
\hline $\begin{array}{l}\text { Mean Difference Between Readings at Baseline } \\
\text { and After } 6 \text { Months }\end{array}$ & -0.142 & 16 & $0.889 \mathrm{NS}$ \\
\hline $\begin{array}{l}\text { Mean Difference Between Readings at Baseline } \\
\text { and After } 1 \text { Year }\end{array}$ & -0.936 & 16 & $0.363 \mathrm{NS}$ \\
\hline $\begin{array}{l}\text { Mean Difference Between Readings After } 6 \\
\text { Months and After } 1 \text { Year }\end{array}$ & -2.266 & 16 & $0.038 \mathrm{~S}$ \\
\hline First Reading at Baseline & -1.021 & 16 & $0.322 \mathrm{NS}$ \\
\hline First Reading After 6 Months & -0.668 & 16 & $0.514 \mathrm{NS}$ \\
\hline First Reading After 1 Year & -0.092 & 16 & $0.928 \mathrm{NS}$ \\
\hline Last Reading at Baseline & -2.069 & 16 & $0.055 \mathrm{NS}$ \\
\hline Last Reading After 6 Months & -2.086 & 16 & $0.053 \mathrm{NS}$ \\
\hline Last Reading After 1 Year & -2.279 & 16 & $0.037 \mathrm{~S}$ \\
\hline
\end{tabular}

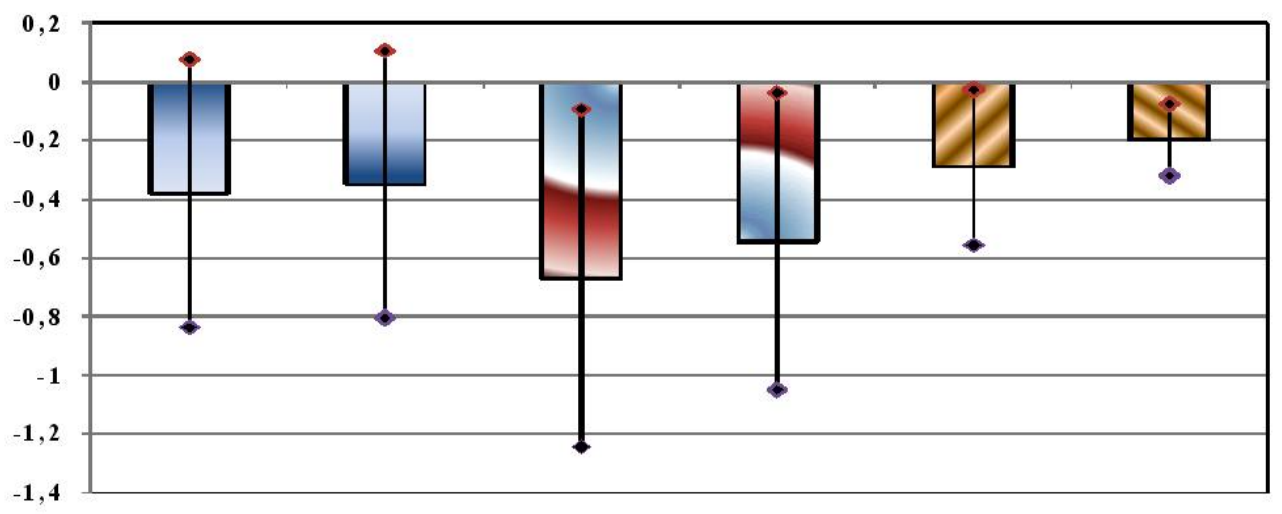

Figure (14): Descriptive statistics concerning mean difference of implant position and effect on alveolar bone resoption between baseline and after 6 months, between baseline and after 1 year and between after 6 months and 12 months(implant position). 


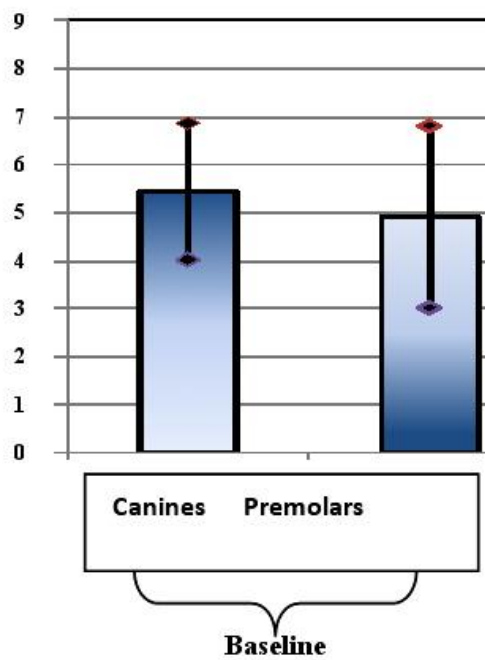

Baseline

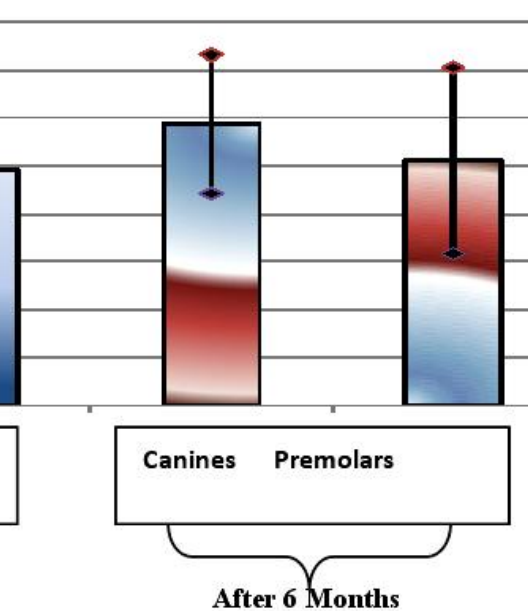

After 6 Months
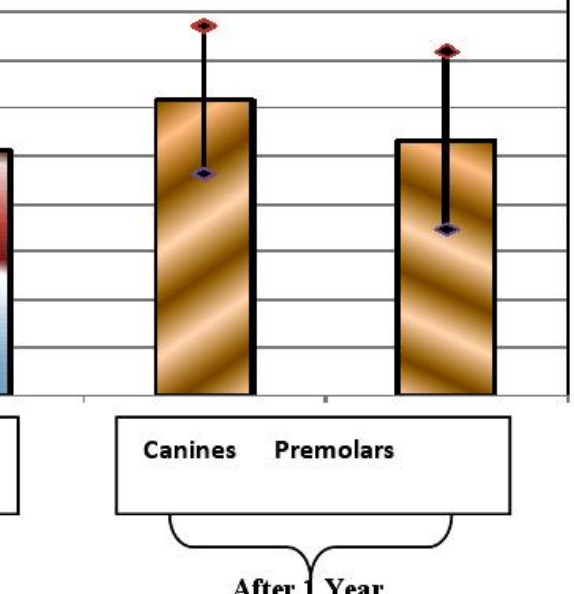

Figure (15): Descriptive statistics of implant position and effect on alveolar bone resoption at first readings: baseline, after 6 months and after 12 months(implant position).

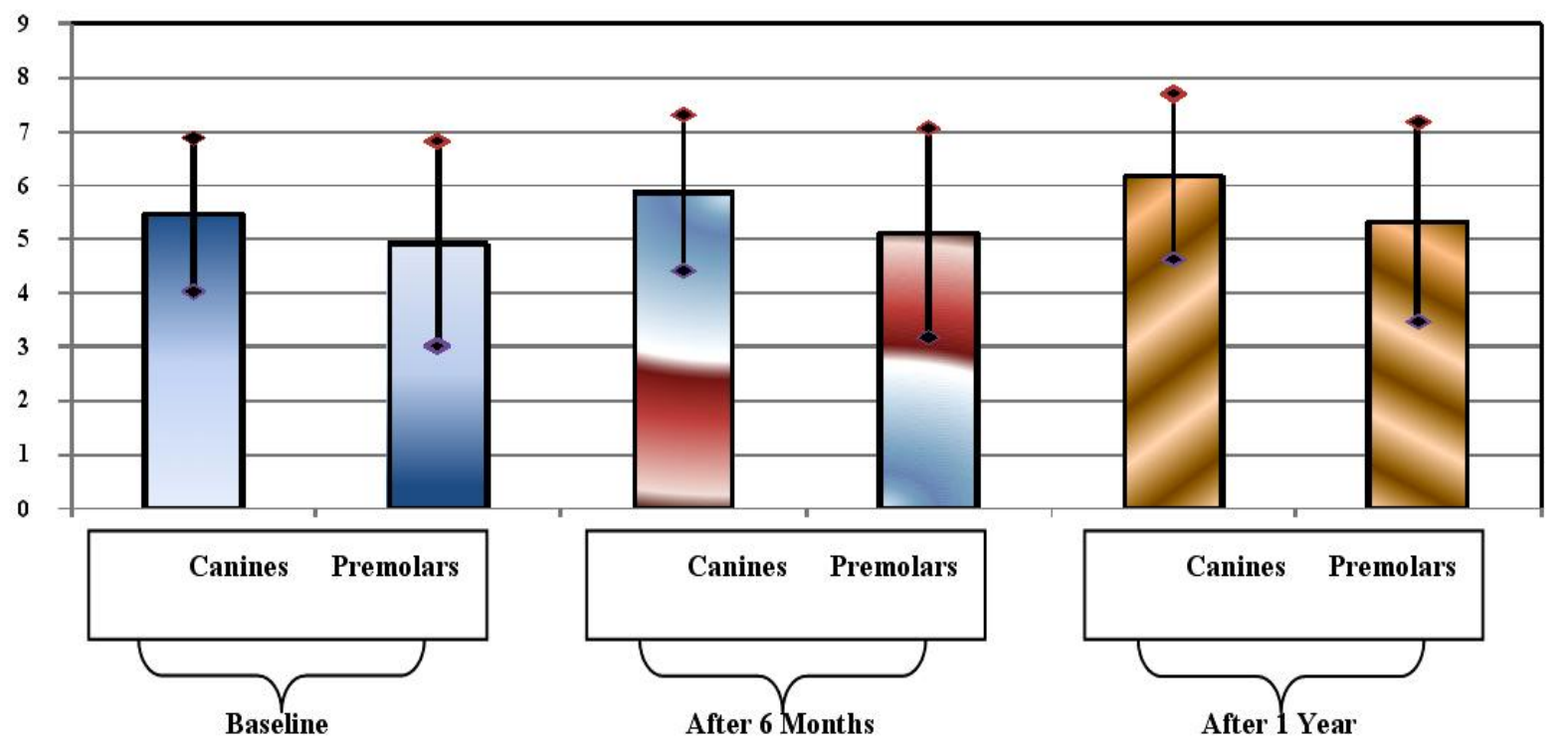

Figure (16): Descriptive statistics of implant position and effect on alveolar bone resoption at last readings: baseline, after 6 months and 12 months. 
Table (3): Student's t-test Canines vs $2^{\text {nd }}$ Premolar

\begin{tabular}{|c|c|c|c|}
\hline Canines vs $2^{\text {nd }}$ Premolar & t-value & d.f. & $p$-value \\
\hline $\begin{array}{l}\text { Mean Difference Between Readings at Baseline } \\
\text { and After } 6 \text { Months }\end{array}$ & -0.180 & 24 & $0.858 \mathrm{NS}$ \\
\hline $\begin{array}{l}\text { Mean Difference Between Readings at Baseline } \\
\text { and After } 1 \text { Year }\end{array}$ & -0.574 & 24 & $0.571 \mathrm{NS}$ \\
\hline $\begin{array}{l}\text { Mean Difference Between Readings After } 6 \\
\text { Months and After } 1 \text { Year }\end{array}$ & -1.074 & 24 & $0.293 \mathrm{NS}$ \\
\hline First Reading at Baseline & 0.831 & 24 & 0.414 NS \\
\hline First Reading After 6 Months & 1.122 & 24 & $0.273 \mathrm{NS}$ \\
\hline First Reading After 1 Year & 1.251 & 24 & $0.223 \mathrm{NS}$ \\
\hline Last Reading at Baseline & -0.141 & 24 & $0.889 \mathrm{NS}$ \\
\hline Last Reading After 6 Months & -0.177 & 24 & $0.861 \mathrm{NS}$ \\
\hline Last Reading After 1 Year & -0.216 & 24 & $0.831 \mathrm{NS}$ \\
\hline
\end{tabular}

d.f $=$ degree of freedom. NS: Non significant result at $p>0.05$.

\section{DISCUSSION}

Correlation between Implant Numbers and Effect on Alveolar Bone Resoption:

*Two Implant Over denture and Four Implant Over denture:

There was no significant difference ( $p>0.05$ ) between the two implants and four implants in most readings but two reading demonstrated significant difference $(p \leq 0.05)$ on alveolar bone resorption.

This investigation was in agreement with other studies which found that despite the prosthetic design, resultant stresses were greater on the side of the load application. The variation in stress intensity and distribution among the 4 loaded prostheses was altered by number and location of implants along the anterior arch, consistent with the work of (Tashkandi et al.; and Mericske) ${ }^{(26,27)}$.

In agreement with results in maxillary arch: stability and support would lead to decrease in alveolar bone resorption for maxillary overdenture in two or four implants ${ }^{(28,29)}$.

\section{Correlation between Implant Position (Canine and $2^{\text {nd }}$ Premolar Regions) and Effect on} Alveolar Bone Resoption:

The present study demonstrated no significant difference $(p>0.05)$ on alveolar bone resorption between canine implant versus $2^{\text {nd }}$ premolar implant at all readings.

In agreement with the results: The use of four mandibular implants in canine and $2^{\text {nd }}$ premolar as Three years later there is no clinical or X-ray evidence about bone resorption ${ }^{(30)}$. The loading of the 2 nd premolar concentrated the stresses over the ipsilateral implant in all $\operatorname{designs}^{(31,32)}$. 


\section{CONCLUSIONS}

The conclusion of this study showed that, there was no significant different of alveolar ridge bone resoption between implants number in two or four implants over denture or implant position during period of 12 months.

\section{REFERENCES}

1. The American Heritage. Medical Dictionary Copyright. by Houghton Mifflin Harcourt Publishing Company. Published by Houghton Mifflin Harcourt Publishing Company, 2009.

2. Petropoulos VC, Smith W, Kousvelari E. Comparison of retention and release periods for implant overdenture attachments. Int J Oral Maxillofac Implants. 1997; 12:176-85.

3. Anne-Sophie B, Guillaume D, Marwan D, Paul L. Influence of implant position on the Behavior of a mandibular implant retained over denture. J. of Bio.2008; 41(1):218-9.

4. Rutkunas V, Mizutani H and Puriene A. Conventional and early loading of two-implant supported mandibular overdentures. A systematic review. Stomatologija, Baltic D. and Maxillo. J.2008; 10(2):51-61.

5. Zmudzki J and Chladek W. Elastic silicone matrices as a tool for load relief in overdenture implants. Acta of Bioengineering and Biomechanics.2008, 10(4):7-10.

6. López-Roldán A, Abad DS, Bertomeu IG, Castillo EG, Otaolaurruchi ES. Bone resorption processes in patients wearing overdentures. A 6-years retrospective study. Med Oral Patol Oral Cir Bucal.2009;14 (4):203-9.

7. Persson RE, Tzannetou S, Feloutzis AG, Brägger U, Persson GR and Lang NP. Comparison between panoramic and intra-oral radiographs for the assessment of alveolar bone levels in a periodontal maintenance population. $J$ Clin Periodontology.2003; 30(9):833-839.

8. Thomas KL. Computed Tomography in Dentistry.The Hong Kong Medical Diary. 2008; 13(11):4-5.

9. Wulfman C, Hadida A, and Rignon-Bret C. Radiographic and surgical guide fabrication for implant-retained mandibular overdenture. J Prosthet Dent.2010; 103(1):53-57

10. Verhoeven JW and Cune MS. Oblique lateral cephalometric radiographs of Jan Willem Verhoeven, the mandible in implantology: usefulness and accuracy of the technique Marco Stephan Cune in height measurements of mandibular bone in vivo. Clin Oral Impl Res.2000; 11: 39-43.

11. Watzak G, Zechner W, Busenlechner D, Arha C, Gruber R, and Watzek G. Radiological and clinical follow-up of machined- and anodized-surface implants after mean functional loading for 33 months. Clin Oral Imp. Res. 2006; 17(6):651-657.

12. Guler AU, Sumer M, Sumer P and Bicer I. The evaluation of vertical heights of maxillary and mandibular bones and the location of anatomic landmarks in panoramic radiographs of edentulous patients for implant dentistry. $J$ Oral Rehabil.2005; 32: 741-746.

13. Vazquez Y, Saulacic N, Belser U and Berna JP. Efficacy of panoramic radiographs in the preoperative planning of posterior mandibular implants: a prospective clinical study of 1527 consecutively treated patients. Clin Oral Implants Reseh.2008; 19(1):81-88

14. Naert I, Koutsikakis G, Duyck J, Quirynen M, Jacobs R and Van Steenberghe D . Biologic outcome of implant supported restorations in the treatment of partial edentulism.Clin Oral Impl Res.2002; 13, 381-389.

15. Sadowsky SJ and Caputo AC. Stress transfer of four mandibular implant overdenture cantilever designs. $J$ Prosthet Dent. 2004; 92(4):328-336.

16. Michal PG, Robert KJ and Thomas DT. Effect of Implant Angulation upon Retention of Overdenture Attachments. J Prosthodont. 2005; 14 (1): 3-11.

17. Watanabe PCA, Issa JPM, Oliverira TM, Monteiro SAC, Iyomasa MM, Regalo SCH and Sissere S. Morphodigital study of the mandibular trabecular bone in panoramic radiographs. Int J Morphol.2007; 25(4):875880 .

18. Selecman AM and Wicks RA. Making an implant-level impression using solid plastic, press-fit, closed-tray impression copings: A clinical report. J Prosthet Dent.2009; 101:158-159.

19. Zarb GA, Bolender CL and Carlsson GE. Prosthetic Treatment for Edentulous Patients.Ch23 Tooth-supported overdentures An organized Approach.,11 ed, Mosby 11830 Westline industrial drive.1997.Pp. 456-8.

20. Chaichanasiri E, Pruettha Nanakorn P, Tharanon W and Sloten JV. Finite Element Analysis of Bone around a Dental Implant Supporting a Crown with a Premature Contact. J Med Assoc Thai.2009; 92 (10):1336-44.

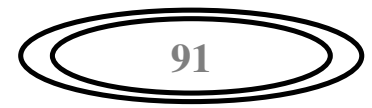


21. Payne AGT, Tawse-Smith, Duncan WD and Kumara R. Conventional and early loading of unsplinted ITI implants supporting mandibular overdentures. Two-year results of a prospective randomized clinical trial. Clin Oral Implants Res.2002; 13:603-609.

22. Hogan L. The Relative Merits of Early Loading versus Immediate Loading in Dental Implants. Thesis of Msc.2008.

23. Taddei C, Metz M, and Etienne O. Direct procedure for connecting a mandibular implant - retained overdenture with ball attachments. J Prosthet Dent.2004; 92(4).402-4.

24. Xie Q, Wolf J, Ainamo A. Quantitative assessment of vertical heights of maxillary and mandibular bones in panoramic radiographs of elderly dentate and edentulous subjects. Acta Odontol Scand. 1997; 55:155-61.

25. Nickenig HJ, Wichmann M, Schlegel KA, Nkenke E, Eitner S. Radiographic evaluation of marginal bone levels adjacent to parallel-screw cylinder machined-neck implants and rough-surfaced microthreaded implants using digitized panoramic radiographs. Clin Oral Impl Res.2009; 20:550-554.

26. Tashkandi EA, Lang BR, Edge MJ. Analysis of strain at selected bone sites of a cantilevered implant-supported prosthesis. J Prosthet Dent.1996; 76: 158-64.

27. Mericske-Stern RD. Force distribution on implants supporting overdentures: the effect of distal bar extensions. A 3-D in vivo study. Clin Oral Implants Res.1997; 8:142-151.

28. Bergendal T, Engquist B: Implant-supported overdentures. A longitudinal prospective study. Int J Oral Maxillofac Implants.1998;13:253-262.

29. Klemetti E, Chehade A, Takanashi Y, Jocelyne SF. Two-Implant Mandibular Overdentures: Simple to Fabricate and Easy to Wear. J Can Dent Assoc.2003; 69(1):29-33.

30. Abadzhiev M and Balcheva M. The Use of Imtec's Mdi Mini-Implants in the treatment of totally edentulous mandible. J. of IMAB.2009; 2:50-51.

31. White SN, Caputo AA, Anderkvist T. Effect of cantilever length on stress transfer by implant-supported prostheses. J Prosthet Dent.1994; 71:493-499.

32. Duyck J, Van Oosterwyck H, Vander Sloten J, De Cooman M, Puers R, Naert I. In vivo forces on oral implants supporting a mandibular overdenture: the influence of attachment system. Clin Oral Investig.1999; 3:201-207. 